\title{
Comparison of the Incidence, Clinical Characteristics, and Outcomes in Otitis Media among US African American and Australian Aboriginal Populations
}

\author{
Tim Baerg ${ }^{1}$, Brian Chang ${ }^{1}$ and Jennifer $\mathrm{Ha}^{2,3 *}$ \\ ${ }^{1}$ University of Michigan Medical School, USA \\ ${ }^{2}$ Department of Surgery, University of Western Australia, Australia \\ ${ }^{3}$ Murdoch ENT, St John of God Hospital (Murdoch), Wexford Medical Centre, Australia
}

Submission: March 25, 2017; Published: April 06, 2017

*Corresponding author: Jennifer Ha, Murdoch ENT, St John of God Hospital (Murdoch), Wexford Medical Centre Suite 17/18, Level 1, 3 Barry Marshall Parade, Murdoch, Western Australia 6150, Tel: +61 8 6332 6868; Fax: +61 86332 6800; Email: drjennha@yahoo.com.au

\begin{abstract}
Otitis media (OM) is the most commonly diagnosed illness in toddlers. Compared to non-indigenous Australian populations, indigenous Australian children are less likely to receive specialty care or surgery for OM. Similarly, compared to non-African American children, African Americans are less frequently diagnosed with $\mathrm{OM}$ and face serious complications because of these disparities. In order to compare and contrast the reasons for the healthcare inequities in both populations, a qualitative narrative review of literature was conducted using the keywords "Aboriginal”, “Indigenous Australian", “African American”, “Otitis Media”, "Disparity”, and "Access." Significant differences were found between the national healthcare systems and types of programs designed to combat these disparities. However, many parallels were discovered between the social factors in both groups leading to the gap in healthcare. This paper seeks to offer a comprehensive of these factors and how they contribute to inequity in care.
\end{abstract}

Keywords: African American; Aboriginal; Indigenous Australian; Otitis media; Access; Socioeconomic status; Healthcare disparity

Abbreviations: AA: African American; ACA: Affordable Healthcare Act; AOM: Acute Otitis Media; ATSI: Aboriginal and Torres Strait Islander; CSOM: Chronic Suppurative Otitis Media; CHL: Conductive Hearing Loss; JCT: Joint Committee on Taxation; MBS: Medicare Benefits Schedule; MEVTI: Middle Ear Ventilation Tubes Insertions; NHE: National Health Expenditure; OM: Otitis Media; OME: Otitis Media with Effusion; RAOM: Recurrent Acute Otitis Media; RCTS: Rural Clinical Training and Support; SES: Socioeconomic Status; SLD: Speech and Language Delay

\section{Introduction}

Otitis media (OM) is the most commonly diagnosed illness in toddlers, making it the number one indication for outpatient antibiotic use in the United States [1,2]. Half of children in the U.S will have OM by 12 months, and 9 out of 10 children by age $5[3,4]$. In Australia, OM is also a major cause for pediatric diagnoses, with $73 \%$ of children being diagnosed with it in their first 12 months and 8 out of 10 children by age 3 [5,6]. Pain, fever, irritability, and conductive hearing loss (CHL) due to OM with effusion (OME) are often associated with recurrent acute OM (RAOM) [7]. In more severe cases, vestibular function may be affected. For instance, OME is the most common cause of balance disorder in children. If permitted to progress to RAOM or chronic suppurative OM (CSOM), lasting effects of CHL with speech and language delay (SLD) may occur. The end result may manifest as poor academic performance, limited social interactions, and inappropriate behavioral issues.

Compared to non-indigenous Australian children, both rural and urban Aboriginal and Torres Strait Islander (ATSI) children suffer from $\mathrm{OM}$ at an earlier age and at a higher frequency, leading to more serious complications [8]. Kong et al. [6] have claimed that among the high-income economy nations, Australian ATSI children are the most predisposed population to both developing $\mathrm{OM}$ and to having acute $\mathrm{OM}(\mathrm{AOM})$ progress to more severe states. No decrease in severe OM complications has been observed in ASTI children over the years, and in some communities, up to $30 \%$ of children develop CSOM [9]. 
Conversely, African American (AA) children with OM are less frequently diagnosed than their White counterparts, resulting in AA children having a higher cumulative proportion of days with OME $[7,10]$. This disparity is interesting because many risk factors that the Australian ATSI have to developing OM are also shared with AA. The discrepancy between the rates of diagnosis within the two populations may underscore underlying medical, sociological, and political differences between the two nations, which in turn, may shed light onto how both countries provide care for marginalized populations. By comparing and contrasting the disparities of $\mathrm{OM}$ in both populations, we explore how medicine is accessed for two socially disenfranchised communities located in the United States and Australia.

\section{Methods}

A qualitative narrative review of the English literature in PubMed, MedLine, CINAHL, Embase, Web of Science and Google Scholar databases was conducted using the keywords "Aboriginal”, “Indigenous Australian", "African American”, “Otitis Media", "Disparity", and "Access". These search terms were purposefully made broad to ensure that relevant studies were not overlooked. The abstracts were scanned for relevance to our review topic. If abstracts were deemed relevant, they were examined in detail. Additionally, gubernatorial sources such as the National Aboriginal and Torres Strait Islander Health Plan were also included in our review.

We identified 357 papers published from 1979 to 2009, 119 of which were relevant to the Australian population and 238 to the American population. In general, much of the existing research underscored socioeconomic issues reflected in underserved communities-especially the AA communityrather than how race specifically plays a role independent of socioeconomics. For instance, findings that explored the role of unconscious bias toward or against racial groups in the diagnosis of OM were not found. Thus, it was difficult to assess an exact cause and effect relationship of race and diagnosis outside of socioeconomic status. Moreover, we found no studies directly comparing the Australian ATSI and the AA populations. Even so, the articles we found provided us with insight onto other associated factors. Longitudinal studies were especially valuable since they naturally captured trends occurring over a long period of time.

\section{Results}

\section{African Americans}

Of the 238 peer reviewed articles about disparities in OM care and outcomes in the AA population, clear trends in differences between diagnosis and treatment emerged. Multiple studies have revealed that the treatment of OM differs by race: non-AA children are more likely than AA children to be referred to subspecialists and receive surgical or antibiotic treatment [11-17]. One study conducted on data from a national database from 2008-2010 showed that that the percentage of clinical visits that resulted in OM diagnoses was $30 \%$ less with AA children compared to non-AA children, even though the percentage of visits for respiratory problems was statistically similar [18]. Moreover, another study showed that AA children were less likely to have access to a regular source of care and have public (vs. private) health insurance, restricting their healthcare options. Even after accounting for these factors, AA children were less likely to see a medical specialist or have surgery for frequent AOM because of issues such as transportation limitations [19].

Several authors have postulated that such differences in treatment regimens may depend on providers' perception of the parents' expectations (e.g. whether antibiotics are necessary): in a study completed in 2004, physicians were found to be more likely to prescribe antibiotics when they perceived that parents expected antibiotics. However, it was discovered that they significantly underestimated the expectations of minority parents [20]. As a result, unconscious bias due to the provider may contribute to the delivery and quality of care. Nevertheless, we found no data accounting for these biases in the specific treatment of $\mathrm{OM}$.

\section{Australian Aboriginal and Torres Straight Islanders}

In the Australian population, stark differences in the treatment of AOM were also found. Non-ATSI children were more likely to be treated promptly for AOM with antibiotics compared to ATSI. For non-ATSI children, within three days, $80 \%$ of infections are expected to be symptom-free [6]. Of those cases that were not resolved exclusively with antibiotics, surgical management including middle ear ventilation tubes insertions (MEVTI) were an important component of healthcare management [21]. On the other hand, ATSI children were less likely to receive antibiotics, ear syringing, and were referred to an audiologist or otolaryngologist at much lower rate [22]. They also showed a greater frequency of natural resolution, and in general were more likely to develop RAOM, leading to more severe symptoms including CSOM: in a study performed by Gunasekera et al. [6,22], ATSI children were over four times as likely to develop CSOM, as well as perforation of the middle ear compared to non-Ingenuous children. Likewise, ATSI children were found to have discharging ears at almost 40 times the rate over non-ATSI children.

In both the AA and ATSI populations, children with OM were less likely to receive specialty care or surgery due to lack of access, whether due to geographical isolation or lack of referral [23-25]. Established risk factors shared between the groups included socioeconomic status (SES) disadvantage, adverse living conditions, domestic overcrowding, and exposure to tobacco smoke $[6,24,26]$. ENREF_24 SES disadvantage in particular was shown to be an important risk factor for developing acute and recurrent OM in both the U.S.A. and Australia, as SES and the development of OM demonstrated a strong, inverse relationship [4,27-35]. 


\section{Discussion}

Differences exist in the incidence and treatment of $\mathrm{OM}$ in ATSIs and AAs. In this review, we underscore three key elements that were found to influence these disparities: the structure of the respective healthcare systems, the social factors influencing the two populations, and the programs developed to combat this inequity.

\section{Health Systems}

While Australia once had a private-pay system, it switched to a universal system with coverage for all citizens in 1984. In doing so, the majority of healthcare spending in the country is now paid for by the government. In 2011-2012, the Australian Government contributed $42.4 \%$ to healthcare spending while the state and territory governments paid for $27.3 \%$ [36]. Australia's Medicare program thus provides patients free treatment, accommodation, and pharmaceutical in a public hospital, and a hard cap on out of pocket costs for medication. Of note, primary health care costs $(36.1 \%$ or $\$ 50.6$ billion) were almost equivalent to the cost of hospital services $(38.2 \%$ or $\$ 53.5$ billion) in 2011-2012, with similar trends in the following years [36]. In recent years, targeted efforts have been made to close the healthcare gap between ATSI and non-ATSI: in 20102011 , approximately $\$ 8000$ was spent on healthcare for every ATSI compared to around $\$ 5500$ for non-ASTI. About $90 \%$ of this funding came from the government [36].

In contrast, the United States primarily still primarily utilizes a private-pay system. $28 \%$ of national health expenditure (NHE) in 2014 was covered by individual households, with out of pocket costs standing at nearly $\$ 330$ billion (over $10 \%$ of NHE) and private health insurance premiums projected to have reached \$1.0 trillion [37]. Such staggering costs favor those in higher income brackets, and those without the financial means to cover these fees often forego preventative care and routine check-ups until it is too late. However, the Affordable Care Act (ACA) has greatly expanded the federal and state government's role in healthcare. Since the ACA was signed into law in 2010, the Office of the Assistant Secretary for Planning and Evaluation has estimated that 17.6 million uninsured people have gained health insurance coverage, and the U.S. uninsurance rate has fallen to the lowest it has been since 2008 (11.0\%) with the uninsurance rate of AA standing at $13.2 \%[38,39]$.

In 2014, it was estimated that Medicare and Medicaid grew to represent $20 \%$ and $16 \%$ of NHE respectively [40]. However, numerous problems still remain with the program. First, those in the lowest income brackets remain hesitant to spend their already limited funds on a service for which they won't immediately see benefits. Even those that have chosen to apply have faced numerous hurdles in applying for insurance, from overcoming technical difficulties on the Obamacare website to gathering proof of income, citizenship, residence, and any other number of requirements [41]. Additionally, nearly $40 \%$ of states (19) have chosen not to expand Medicaid since the implementation of the ACA, leaving around 4 million adults nationally whose income is above Medicaid eligibility but below that for which they can earn Marketplace premium tax credits [42]. Of these adults, around a quarter of the individuals in the coverage gap are black [43]. Finally, for those with their own insurance, the costs of healthcare remain prohibitively expensive for some even after subsidies and tax credits: the Congressional Budget Office and the staff of the Joint Committee on Taxation (JCT) project that in 2016, the average premium for employment-based individual coverage will be around $\$ 6,400$ and $\$ 15,500$ for family coverage [44]. All of this combined indicates the intricacy of the U.S. healthcare system and just how daunting and difficult it may be to obtain insurance.

\section{Social Factors}

While many intrinsic differences between the AA and ATSI populations exist with regards to population and healthcare policy, their history and present status of medical disenfranchisement are similar. Both groups share a similar distrust of the medical system, made in part by the fact that their healthcare systems are perceived to be made up of a mainly majority population that has historically established oppression. In the AAs community, the history of mistrust took roots in the time of slavery and was exaggerated through in the time of Jim Crow, exemplified by experiments in the Tuskegee study [45]. In a cross-sectional analysis performed in Detroit to assess differences in the perception of medical research, results demonstrated that AAs were less likely to believe that they were equally subject to risks in research when compared Caucasians. $81 \%$ of the AAs polled reported that they knew of the Tuskegee study while only $28 \%$ of Caucasians reported awareness. Consequently, $51 \%$ of AAs stated that they had decreased trust in medicine compared to only $17 \%$ of Caucasians [46].

In Australia, ATSIs have also perceived the healthcare system as a place of harm instead of healing. From roughly 1871 to 1969 , many ATSIs were forcibly removed from their homes to live in social institutions, foster homes, adoptive families and forced employment [47]. Reports of the ongoing medical, psychological and emotional problems, addictions, mental illness, incarceration, violence, self-harm and suicide have been shared from those in the so called "Stolen Generations" [48]. Such a history of unethical social marginalization may contribute to wariness felt by some ATSI to trust their medical system.

\section{Programs to Combat Inequality}

ATSIs benefit from the Aboriginal and Torres Strait Islander Health Services, a federal healthcare service funded both by the national and state/territory governments. The overall objective of the initiative is to deliver "targeted, evidence-based action that will contribute to achieving equality of health status and life expectancy between Aboriginal and Torres Strait Islander people and non-Indigenous Australians by 2031" [49]. To achieve this 
mission, the program provides ATSI-targeted healthcare with auxiliary funding in concert to Medicare Benefits Schedule (MBS) funded services. Additional federal programs such as the Australian Government's Rural Clinical Training and Support (RCTS) program target this population more indirectly, working broadly with medical schools and health programs to increase the number of healthcare workers practicing in regional and rural Australia [46].

Partnerships with ATSI organizations including the Australian Indigenous Doctors' Association and the Leaders in Indigenous Medical Education Network ensure that students gain a more comprehensive understanding of Indigenous populations, from the more common chronic conditions to the cultural ATSI practices [50]. At the same time, regional programs seek to improve the quality of healthcare afforded to ATSIs. The Greater Northern Australian Regional Training Network, for example, provides supplemental training for healthcare workers engaging ATSI populations, while the Western Desert Kidney Project has developed an innovative diabetes screening program, incorporating a community arts program to disseminate "culturally appropriate health messages" as well as community development officer to work on "structural issues" such as advocacy and grant applications [50,51]. Beyond generalists, otolaryngology programs such as the Ear Bus Foundation and the Western Australian Coutry Health Service's Kimberly ENT Outreach Clinic offer services targeted to $\mathrm{OM}$ and ear related disorders [52,53].

In the U.S., numerous programs from the federal to the regional levels seek to eliminate healthcare inequality among racial and ethnic minorities at large. At a federal level, the U.S. Department of Health \& Human Services Office of Minority Health provides funding to support "public and private community-based practices" to close the healthcare gap, and develops mandates and guidelines to provide culturally appropriate services, especially for those with limited proficiency in English [36]. Nationally, organizations including the National Association for the Advancement of Colored People target issues of obesity, HIV, and other chronic conditions among AAs, while also engaging in key political battles for healthcare reform [54]. In key contrast to Australian attempts to eliminate healthcare inequities among the Indigenous population, U.S. federal programs target all minorities, and not just AAs. In theory, funding and support is proportionately distributed to each ethnicity/race. However, how money, time, and effort are actually spread is unknown, and may very well contribute to the disparities encountered by the AA population.

An area for further investigation includes how the provider's perception of the patients specifically influence OM diagnosis and treatment. While the nexus of race and socioeconomic status has been explored, the influence of racial biases independent of socioeconomic status has not been document in either the AA or ATSI with regards to OM. These results would allow for a better evaluation of how the intersection of race and medicine compare the United States and in Australia.

\section{Conclusion}

While both AA and Australian ATSI face poorer healthcare outcomes than their majority peers, the incidence of reported OM differs among the two groups. Since Australia's healthcare system allows for better accessibility for those of lower socioeconomic status, ATSI have a higher rate of diagnoses than non-ATSI populations, indicating that race is a risk factor for $\mathrm{OM}$ in Australia. It is possible that lower income AA also have higher rates of $\mathrm{OM}$ than non-AA due to other shared risk factors, but due to financial barriers, are less likely to seek medical care.

\section{Acknowledgement}

We would like to thank Drs. Brent Williams and Mary Heisler for their guidance regarding an unexplored review topic and feedback concerning the research process.

\section{References}

1. Schappert SM (1992) Office visits for otitis media: United States, 197590. Adv Data (214): 1-19.

2. McCaig LF, Hughes JM (1995) Trends in antimicrobial drug prescribing among office-based physicians in the United States. JAMA 273(3): 214219.

3. Teele DW, Klein JO, Rosner B (1989) Epidemiology of otitis media during the first seven years of life in children in greater Boston: a prospective, cohort study. J Infect Dis 160(1): 83-94.

4. Paradise JL, Rockette HE, Colborn DK, Bernard BS, Smith CG, et al. (1997) Otitis media in 2253 Pittsburgh-area infants: prevalence and risk factors during the first two years of life. Pediatrics 99(3): 318-333.

5. Taylor PS, Faeth I, Marks MK (2009) Cost of treating otitis media in Australia. Expert review of pharmacoeconomics \& outcomes research 9(2): 133-141.

6. Kong K, Coates HL (2009) Natural history, definitions, risk factors and burden of otitis media. The Medical journal of Australia 191(9): S3943.

7. Smith DF, Boss EF (2010) Racial/ethnic and socioeconomic disparities in the prevalence and treatment of otitis media in children in the United States. The Laryngoscope 120(11): 2306-2312.

8. Morris PS, Leach AJ, Silberberg P, Mellon G, Wilson C, et al. (2005) Otitis media in young Aboriginal children from remote communities in Northern and Central Australia: a cross-sectional survey. BMC pediatrics 5:27.

9. Leach AJ, Morris PS, Silberberg P, Mellon G, et al. (2001) Perspectives on infective ear disease in indigenous Australian children. Journal of paediatrics and child health 37(6): 529-530.

10. Teele DW, Klein JO, Chase C, Menyuk P, Rosner BA (1990) Otitis media in infancy and intellectual ability, school achievement, speech, and language at age 7 years. Greater Boston Otitis Media Study Group. The Journal of infectious diseases. 162(3): 685-694.

11. Griffith TE (1979) Epidemiology of otitis media--an interracial study. The Laryngoscope 89(1): 22-30.

12. Bush PJ, Rabin DL (1980) Racial differences in encounter rates for otitis media. Pediatric research. 14(10): 1115-1117.

13. Shurin PA, Pelton SI, Donner A, Klein JO (1979) Persistence of middle- 
ear effusion after acute otitis media in children. The New England journal of medicine. 300(20): 1121-1123.

14. Teele DW, Klein JO, Rosner BA (1980) Epidemiology of otitis media in children. Ann Otol Rhinol Laryngol Suppl 89(3): 5-6.

15. Marchant CD, Shurin PA, Turczyk VA, Wasikowski DE, Tutihasi MA, et al. (1984) Course and outcome of otitis media in early infancy: a prospective study. J Pediatr 104(6): 826-831.

16. Wright PF, Sell SH, McConnell KB, Sitton AB, Thompson J, et al. Impact of recurrent otitis media on middle ear function, hearing, and language. J Pediatr 113(3): 581-587.

17. Gerber JS, Prasad PA, Localio AR, Fiks AG, Grundmeier RW, et al. (2013) Racial differences in antibiotic prescribing by primary care pediatricians. Pediatrics 131(4): 677-684.

18. Fleming Dutra KE, Shapiro DJ, Hicks LA, Gerber JS, Hersh AL et al. (2014) Race, otitis media, and antibiotic selection. Pediatrics 134(6): 1059-1066.

19. Park CH, Kogan MD, Overpeck MD, Casselbrant ML (2002) Black-white differences in health care utilization among US children with frequent ear infections. Pediatrics 109(5): E84-84.

20. Mangione-Smith R, Elliott MN, Stivers T, McDonald L, Heritage J, et al. (2004) Racial/ethnic variation in parent expectations for antibiotics: implications for public health campaigns. Pediatrics. 113(5): e385394.

21. (2008) Australian hospital statistics 2006-07. In: Welfare AIoHa, ed. Online: Australian Government.

22. Gunasekera H, Knox S, Morris P, Britt H, McIntyre P, et al. (2007) The spectrum and management of otitis media in Australian indigenous and nonindigenous children: a national study. Pediatr Infect Dis J 26(8): 689-692.

23. Jervis-Bardy J, Sanchez L, Carney AS (2014) Otitis media in Indigenous Australian children: review of epidemiology and risk factors. J Laryngol Otol 128 Suppl 1: S16-27.

24. Dunbar JA, Peach E (2012) The disparity called rural health: what is it, and what needs to be done? Aust J Rural Health 20(6): 290-292.

25. Vernacchio L, Lesko SM, Vezina RM, Corwin MJ, Hunt CE, et al. (2004) Racial/ethnic disparities in the diagnosis of otitis media in infancy. Int J Pediatr Otorhinolaryngol 68(6): 795-804.

26. Ambrosio A, Brigger MT (2014) Surgery for Otitis Media in a Universal Health Care Model: Socioeconomic Status and Race/Ethnicity Effects. Otolaryngol Head Neck Surg 151(1): 137-141.

27. Howie PW, Forsyth JS, Ogston SA, Clark A, Florey CD (1990) Protective effect of breast feeding against infection. BMJ 300(6716): 11-16.

28. Sipila M, Karma P, Pukander J, Timonen M, Kataja M (1988) The Bayesian approach to the evaluation of risk factors in acute and recurrent acute otitis media. Acta Otolaryngol 106(1-2): 94-101.

29. Kero P, Piekkala P (1987) Factors affecting the occurrence of acute otitis media during the first year of life. Acta Paediatr Scand 76(4): 618-623.

30. Robinson M (1951) Infant morbidity and mortality. A study of 3266 infants. Lancet 1(6658): 788-793.

31. Stahlberg MR, Ruuskanen O, Virolainen E (1986) Risk factors for recurrent otitis media. Pediatr Infect Dis 5(1): 30-32.
32. Unni JC, Richard J (1988) Growth and morbidity of breast-fed and artificially-fed infants in urban south Indian families. J Trop Pediatr 34(4): 179-181.

33. Cunningham AS (1979) Morbidity in breast-fed and artificially fed infants. II. J Pediatr 95(5 Pt 1): 685-689.

34. Johonnott SC (1973) Differences in chronic otitis media between rural and urban Eskimo children: a comparative study. Clin Pediatr (Phila) 12(7): 415-419.

35. Cambon K, Galbraith JD, Kong G (1965) Middle-ear disease in Indians of the Mount Currie Reservation, British Columbia. Can Med Assoc J 93(25): 1301-1305.

36. Welfare AIoHa (2014) Australia's health system. Australia's health.

37. Services CfMa M (2016) NHE Fact Sheet.

38. Health insurance coverage and the Affordable Care Act. In: Evaluation OotASfPa, ed. Online: U.S.A. Government; 2015.

39. Marken S (2016) U.S. uninsured rate at $11.0 \%$, lowest in eight-year trend. Healthcare.

40. NHE Fact Sheet. In: Services CfMM, ed. Online: U.S.A. Government; 2014.

41. (CMCS) CfMaCS. Eligibility. https://www.medicaid.gov/medicaid/ eligibility/index.html. Accessed October 18, 2016.

42. Garfield RDA (2016) The coverage gap: uninsured poor adults in states that do not expand Medicaid - an update. Health Reform.

43. Wiltz T (2015) Many African-Americans fall into a health 'coverage gap'. Stateline.

44. Private health insurance premium federal policy. In: Office $C B$, ed. Online: U.S.A. Government; 2016

45. Murray TM (2015) Trust in African Americans' Healthcare Experiences. Nurs Forum 50(4): 285-292.

46. Shavers VL, Lynch CF, Burmeister LF (2002) Racial differences in factors that influence the willingness to participate in medical research studies. Ann Epidemiol 12(4): 248-256.

47. Health AGDo (2013) National Aboriginal and Torres Strait Islander Suicide Prevention Strategy. 1-48.

48. Haebich A (2011) Forgetting Indigenous histories: cases from the history of Australia's stolen generations. Journal of Social History 44(4): 14 .

49. (2013) National Aboriginal and Torres Strait Islander health plan 2013-2023. In: Welfare AIoHa, ed: Australian Government.

50. Greenhill JA, Walker J, Playford D (2015) Outcomes of Australian rural clinical schools: a decade of success building the rural medical workforce through the education and training continuum. Rural Remote Health 15(3): 2991.

51. Sinclair C, Stokes A, Jeffries-Stokes C, Daly J (2016) Positive community responses to an arts-health program designed to tackle diabetes and kidney disease in remote Aboriginal communities in Australia: a qualitative study. Aust N Z J Public Health 40(4): 307-312.

52. Serafino S, Campbell A (2015) Kimberly Health Profile. In: Unit PaE, ed 1-60.

53. Australia EFoW (2016) Earbus Program.

54. (2015) Health programs. 
(C) Commons Attribution 4.0 License

DOI: $10.19080 /$ GJ0.2017.06.555684

\section{Your next submission with Juniper Publishers will reach you the below assets}

- Quality Editorial service

- Swift Peer Review

- Reprints availability

- E-prints Service

- Manuscript Podcast for convenient understanding

- Global attainment for your research

- Manuscript accessibility in different formats

( Pdf, E-pub, Full Text, Audio)

- Unceasing customer service

Track the below URL for one-step submission https://juniperpublishers.com/online-submission.php 